REVIEW ARTICLE

\section{Escherichia coli STb enterotoxin}

\author{
J. Daniel Dubreuil
}

Tel: +15147738521 ext. 8433. Fax $:+1514778$ 8108. e-mail: dubreuid@ere.umontreal.ca

Département de pathologie et microbiologie vétérinaires, Faculté de médecine vétérinaire, Université de Montréal, Saint-Hyacinthe (Québec), Canada J2S 7C6

Keywords: Escherichia coli, STb enterotoxin, heat-stable toxin, diarrhoea, pathogenesis

\section{Overview}

Enterotoxigenic Escherichia coli (ETEC) can cause severe diarrhoea in humans and animals by production of two distinct types of enterotoxin, a heat-labile enterotoxin (LT) with two subtypes (LTI and LTII) and a family of heat-stable enterotoxins (ST) (Söderlind et al., 1988). These enterotoxins reversibly alter normal intestinal homeostasis, causing intestinal secretion and diarrhoea (Betley et al., 1986, Weikel et al., 1986a). LT is a high-molecular-mass toxin $(85 \mathrm{kDa})$ functionally and structurally related to Vibrio cholerae toxin (Sprangler, 1992). STs are low-molecular-mass toxins that retain toxic activity after incubation at $100^{\circ} \mathrm{C}$ for $30 \mathrm{~min}$, whereas LT loses activity under these conditions (Weikel et al., 1986a).

In 1978, Burgess et al. demonstrated that two types of ST were produced by E. coli; one toxin was methanolsoluble and active in the intestine of infant mice (STa), the other was methanol-insoluble, inactive in infant mice, but active in ligated intestinal segments of newborn and weaned piglets (STb). At that time, heat-stable enterotoxin was used as a generic term (ST) including STa and STb. The terms STI and STII are also commonly used as synonyms for STa and STb, respectively (Handl et al., 1988). Although the identity of $\mathrm{ST}$ toxin was established almost two decades ago, only recently did it attract sufficient interest to allow recognition of a new mechanism of action distinct from that of other known toxins. In the last few years, studies on the chemical and physical features, genetics and immunogenicity of STb have shed light on this intriguing yet neglected enterotoxin.

This review aims at summarizing the current knowledge of $\mathrm{STb}$. It will be limited to $\mathrm{STb}$ enterotoxin; for information on LT and STa enterotoxins, readers are referred to the following reviews: $\mathrm{Li}$ (1992); Sprangler (1992); Gyles (1994); Sears \& Kaper (1996).

\section{Clinical importance of STb}

Since the discovery of STb toxin in the late 1970s, numerous studies have set out to determine its im- portance in diarrhoeal illnesses. Firstly, epidemiological studies were conducted to establish the role of STb in disease by relating the presence or absence of STb with diarrhoea in animals. Then, since ETEC strains must possess colonization factors that permit adhesion and colonization of the small intestinal epithelium, many studies focused on establishing a relationship between the presence of specific fimbrial adhesins and the presence of enterotoxins. Several researchers have also investigated the putative association of serotype and toxin production. In these investigations, $\mathrm{STb}$ was determined using DNA probes to detect, by hybridization, the presence or absence of the enterotoxin genes. The adhesins were detected and identified using either DNA probes or antibodies. STb has historically been associated mainly with ETEC of porcine origin. However, a more thorough examination of bovine, chicken and even human ETEC strains has revealed the presence of the STb gene in some of these strains also.

\section{Porcine strains}

Production of STb is principally, but not solely, associated with porcine ETEC and although STb is usually found in combination with one or several enterotoxins, a significant number of ETEC strains produce STb only. These strains were important in establishing the role of the toxin in diarrhoea. As early as 1980, Moon et al. demonstrated the existence of ETEC strains that were $\mathrm{LT}^{-}, \mathrm{STa}^{-}$and $\mathrm{STb}^{+}$(Table 1). In the same study, neonatal pigs experimentally inoculated with an $\mathrm{LT}^{-}$, $\mathrm{STa}^{-}$and $\mathrm{STb}^{+}$strain producing the colonization factor $\mathrm{F}_{5}$ (K99) adhered to villi, intensively colonized the ileum and caused profuse diarrhoea, indicating clearly an active role of $\mathrm{STb}$ in animals. On the other hand, three STb-producing ETEC strains that did not seem to possess any of the tested fimbriae $\left(F_{4}, F_{5}\right.$ and $F_{6}$, previously known as K88, K99 and 987P, respectively) were observed. One of these strains was shown to produce $\mathrm{F}_{6}$ fimbriae after in vivo growth, indicating that for certain strains, fimbriae are produced only if the isolate is passaged in vivo.

Numerous epidemiological studies using hybridization techniques and enterotoxin gene probes were done on 
Table 1. Studies on porcine STb ${ }^{+}$ETEC strains as determined with DNA probes and by the presence of diarrhoea in pigs

\begin{tabular}{|c|c|c|c|c|c|c|}
\hline \multirow[t]{2}{*}{ Reference } & \multirow[t]{2}{*}{ O-types } & \multicolumn{4}{|c|}{ Fimbrial antigen } & \multirow[t]{2}{*}{ Diarrhoea* } \\
\hline & & $\mathbf{F}_{4}$ & $\mathrm{~F}_{5}$ & $F_{6}$ & Type 1 & \\
\hline Moon et al. (1980) & ND & - & + & - & ND & + \\
\hline de Castro et al. (1984) & O18, O115, O119 & ND & ND & ND & ND & + \\
\hline Wilson \& Francis $(1986)$ & $\begin{array}{l}\text { O8, O20, O101, O141, } \\
\text { O149, O157 }\end{array}$ & + & - & + & + & + \\
\hline Fairbrother et al. (1988) & $\mathrm{O} 20$ & - & + & - & ND & + \\
\hline Monckton \& Hasse (1988) & ND & + & - & ND & ND & + \\
\hline Söderlind et al. (1988) & ND & - & - & - & ND & - \\
\hline Fairbrother et al. (1989) & $\mathrm{O} 115$ & - & - & - & ND & + \\
\hline Nagy et al. (1990) & $\begin{array}{l}\text { O141, O147, O149, } \\
\text { O157 }\end{array}$ & + & - & - & ND & + \\
\hline Harel et al. (1991) & $\begin{array}{l}\text { O8, O64, O115, O138, } \\
\text { O139, O147, O149, } \\
\text { O157 }\end{array}$ & + & + & - & ND & + \\
\hline Osek \& Truszczynski (1992) & ND & + & - & - & - & + \\
\hline $\begin{array}{l}\text { J. M. Fairbrother, } \\
\text { personal communication }\end{array}$ & ND & - & - & - & ND & + \\
\hline
\end{tabular}

ND, Not determined.

*As observed with ETEC STb ${ }^{+}, \mathrm{STa}^{-}$and $\mathrm{LT}^{-}$isolates.

large numbers of $E$. coli isolates to determine the causal association of STb with diarrhoeal illnesses. For example, Moon et al. (1986) showed that $74 \%$ of ETEC isolated from swine with enteric colibacillosis hybridized with the STb probe. Interestingly, $33 \%$ of ETEC from swine more than 1 week of age with enteric colibacillosis were positive for STb only. The association of $\mathrm{STb}^{+}$strains with colibacillosis was confirmed in various studies (de Castro et al., 1984; Wilson \& Francis, 1986; Fairbrother et al., 1988; Monckton \& Hasse, 1988).

Different research groups established that isolates positive for $\mathrm{STb}$ were also positive for other enterotoxins. The most prevalent enterotoxin gene combination observed was LT-STb (Moon et al., 1986; Wilson \& Francis, 1986; Nagy et al., 1990; Harel et al., 1991; Osek \& Truszczynski, 1992). Studies of the association of STb with adhesion factors and with strain serotype were also conducted (Table 1). $\mathrm{F}_{4}$ fimbriae were most often associated with $\mathrm{STb}^{+}$strains. $\mathrm{STb}$ production was observed for many $E$. coli serotypes and its production was not restricted to particular serotypes.

Other studies revealed the existence of E. coli $\mathrm{STb}^{+}$ strains for which no adhesion factors were found. Two of these strains were used to inoculate newborn piglets that had suckled from their mother and no symptoms were induced (Söderlind et al., 1988). In contrast, Fairbrother et al. (1989) demonstrated that $\mathrm{STb}^{+}$strains without any known adhesion factor could cause diarrhoea in experimentally inoculated newborn piglets.

In Hungary, Nagy et al. (1990) showed that $25 \%$ of the tested isolates produced one or more of the toxins STa (also called STaP), STb and verotoxin (VT) without any known adhesins. Woodward \& Wray (1990) similarly examined $1031 \mathrm{E}$. coli strains isolated from cattle and pigs with diarrhoea and observed that $24 \%$ of all toxigenic strains apparently did not possess adhesins. A possible explanation of the pathogenicity of $\mathrm{STb}^{+}$strains for which no adhesion factor can be detected is that these strains produce adhesion factors that are yet to be identified and characterized. For example, Kennan \& Monckton (1990) described new adhesive fimbriae associated with porcine ETEC possessing STa and STb genes. An antiserum raised against the purified pilin did not cross-react with $\mathrm{F}_{4}, \mathrm{~F}_{5}$ or $\mathrm{F}_{6}$ fimbriae.

$\mathrm{STb}$-induced colibacillosis seems to depend on the age of the animal. ETEC isolated from piglets with diarrhoea (333 isolates) at the age of $1-4$ weeks produced one of the combinations of enterotoxins STb and STa (14.9\%), STb and LT $(52 \cdot 1 \%)$ or STb alone $(29.8 \%)$; piglets with diarrhoea at more than 4 weeks of age (412 isolates) produced the combinations STb and STa $(20 \cdot 4 \%)$, STb and LT $(28.6 \%)$ or STb alone $(33.4 \%)$. Most of the ETEC producing STb alone did not produce any of the known fimbrial antigens (J. M. Fairbrother, personal communication). Before 1 week of age, the number of strains producing only STb is lower $(17 \%$ ) (Moon et al., 1986).

Thus, it seems that the STb gene is closely related to diarrhoea seen in pigs but can also be present in some ETEC strains isolated from healthy animals. The association of $\mathrm{STb}^{+}$strains with healthy animals could be explained by the absence of adhesion structures, nonsusceptibility of individual animals, the absence of 
predisposing environmental conditions or the production of minute amounts of toxin. In fact, E. coli strains can produce different amounts of STb toxin (Dubreuil et al., 1991). The STb gene, although quite often found in association with the LT gene, is found predominantly as the single enterotoxin determinant in ETEC, which are isolated mostly from diarrhoeic animals.

\section{Human strains}

The presence of STb in ETEC strains of human origin was investigated to ascertain the animal species specificity of $\mathrm{STb}$. Echeverria et al. (1984) reported the isolation of E. coli strains possessing the gene for STb from humans in Thailand. One $\mathrm{STb}^{+}$strain was isolated from a farmer without a recent history of diarrhoea. In a subsequent study, 1 ETEC strain hybridizing with the $\mathrm{ST}$ b probe was found in 1 of 177 villagers with diarrhoea and in 12 of 1307 without diarrhoea (Echeverria et al., 1985a). The $\mathrm{STb}^{+}$E. coli strain isolated from a woman with diarrhoea, and two strains isolated from villagers without diarrhoea, also contained the genes encoding LT. In this last study, $\mathrm{STb}^{+}$ETEC was shown to have been acquired from pigs.

Lortie et al. (1991c) reported that the gene encoding STb was detected in two $E$. coli strains isolated from the stools of humans with diarrhoea. Those two strains were also positive for cytolethal distending toxin (CLDT) and porcine heat-labile enterotoxin (LT1p). This study also demonstrated that, at least in those two human strains, the gene encoding $\mathrm{STb}$ was correctly expressed and that the enterotoxin produced was active in rat jejunal loops. However, these two strains lacked the classical fimbriae associated with animal ETEC. A causal relationship with diarrhoea could not be established in this case. ETEC strains isolated from children with diarrhoea under the age of 5 years in 4 tropical countries [Bangladesh (50 strains), Gambia (39), New Guinea (13) and Nicaragua (77)] were studied by Handl \& Flock (1992). Only one of those isolates, originating from Nicaragua, was $\mathrm{STb}^{+}$and also produced LT and STa.

Okamoto et al. (1993) examined the production of STb by $E$. coli isolated from patients with traveller's diarrhoea. Of 400 strains examined, 3 produced STb. As in the study of Lortie et al. (1991c), they showed the STb gene sequence to be identical to that of porcine strains. The cultured E. coli strains induced fluid accumulation in ligated mouse intestinal loops. Fluid accumulation was neutralized by anti-STb antiserum to discriminate the effect of STb from that of LT1p which was also produced by these strains. Because fluid accumulation was noted in the absence of a protease inhibitor, these workers believed that their study strongly suggested that $\mathrm{STb}$ is occasionally a cause of human diarrhoea. Nevertheless, the role of STb in diarrhoea in humans remains to be determined. The low frequency of $\mathrm{STb}^{+}$ human strains suggests that this enterotoxin could contribute, on rare occasions, to human diarrhoeal disease. $\mathrm{STb}^{+}$human ETEC isolates are most probably acquired from animals (e.g. pigs) and the role of STb in human diarrhoea has not yet been established directly. Thus, further studies are necessary to draw more definite conclusions about the enteropathogenicity of STb in humans.

\section{Bovine strains}

The STb gene is also found occasionally in ETEC strains isolated from cattle. Mainil et al. (1986) showed that $5 \%$ of the E. coli strains isolated from calves carried the $\mathrm{STb}$ and LT genes. Another study by Mainil et al. (1990) of 870 ETEC strains isolated from cattle in Belgium revealed the absence of $\mathrm{STb}^{+}$strains. However, 7 of 12 bovine isolates obtained from the USA, tested in the same study, were positive for $\mathrm{STb}$ and for $\mathrm{F}_{6}$ fimbriae. Work by Shin et al. (1994) indicated that $1 \cdot 1 \%$ of the 666 bovine isolates from the USA hybridized with the STb probe. Echeverria et al. (1985a) found one ETEC strain hybridizing with an STb probe in 162 water buffaloes. Thus, it seems that bovine ETEC strains carrying the $\mathrm{STb}$ gene are rare and none of the studies related the presence of the strains to diarrhoeal illnesses in the animal.

\section{Chicken strains}

Only one investigation (Akashi et al., 1993) reported the isolation of $E$. coli strains containing the STb gene 7 of 38 strains) from the stools of chickens with diarrhoea. Culture supernatants from these strains induced fluid accumulation in the mouse intestinal loop test. When culture supernatants were tested in chicken intestinal loops, in the absence of the protease inhibitor required to obtain a positive response in mouse and rat loop assays, fluid accumulation was nevertheless observed. Production of STb at the chicken body temperature $\left(41^{\circ} \mathrm{C}\right)$ was observed and overall it was concluded that STb must play a role in chicken diarrhoeal diseases. No other studies on chicken ETEC isolates producing $\mathrm{STb}$ has been done to corroborate these data.

\section{STb assays}

Using the pig ligated intestine technique, Smith \& Halls (1967) were the first to identify an E. coli cell-free heatstable preparation that caused fluid accumulation. This demonstration of a heat-stable, enterotoxin-induced intestinal fluid response by culture supernatants of porcine diarrhoeagenic $E$. coli strains was confirmed by Smith \& Gyles (1970) who coined the acronyms ST for stable toxin and LT for labile toxin.

As mentioned previously, Burgess et al. (1978) demonstrated that two distinct types of ST were elaborated by some E. coli strains. These heat-stable enterotoxins could be differentiated on the basis of methanol solubility, STb being precipitated by this organic solvent. Later it was found that the two enterotoxins could also be differentiated on the basis of their biological activity in different animal species (Whipp et al., 1981; Weikel et al., 1986c) leading to elaboration of in vivo assays in different animal species (Table 2 ). 
Table 2. In vivo and in vitro STb assays

(a) In vivo assays

\begin{tabular}{|c|c|c|c|}
\hline Animal species & Assay & Protease inhibitor & Reference \\
\hline $\left.\begin{array}{l}\text { Y'ig } \\
\text { Calf } \\
\text { L.amb } \\
\text { Rabbit }\end{array}\right\}$ & $\begin{array}{l}\text { Intestinal loop } \\
\text { Oral administration }\end{array}$ & $\left.\begin{array}{l}\text { None } \\
\text { None }\end{array}\right\}$ & Smith \& Halls (1967) \\
\hline Pig & Intestinal loop (small intestine) & None & Smith \& Gyles (1970) \\
\hline Pig & Intestinal loop (jejunum) & Soybean trypsin inhibitor & Whipp (1987) \\
\hline $\begin{array}{l}\text { Pig } \\
\text { Mouse (infant) }\end{array}$ & $\begin{array}{l}\text { Intestinal loop (jejunum) } \\
\text { Oral administration }\end{array}$ & $\left.\begin{array}{l}\text { Soybean trypsin inhibitor } \\
\text { Soybean trypsin inhibitor }\end{array}\right\}$ & Whipp (1990) \\
\hline $\left.\begin{array}{l}\text { Pig } \\
\text { Mouse } \\
\text { Rat } \\
\text { Rabbit } \\
\text { Calf }\end{array}\right\}$ & Intestinal loop (jejunum) & Soybean trypsin inhibitor & Whipp (1991) \\
\hline Ciuinea-pig & Intestinal loop (ileum) & None & Choudhry et al. (1991) \\
\hline $\begin{array}{l}\text { Rat } \\
\text { Mouse (infant) }\end{array}$ & $\begin{array}{l}\text { Intestinal loop (jejunum) } \\
\text { Oral administration }\end{array}$ & $\left.\begin{array}{l}\text { Aprotinin } \\
\text { Aprotinin }\end{array}\right\}$ & Fujii et al. (1991) \\
\hline $\begin{array}{l}\text { Mouse } \\
\text { Mouse (infant) }\end{array}$ & $\begin{array}{l}\text { Intestinal loop (ileum) } \\
\text { Oral administration }\end{array}$ & $\left.\begin{array}{l}\text { None } \\
\text { None }\end{array}\right\}$ & Hitotsubashi et al. $(1992 \mathrm{a}, \mathrm{b})$ \\
\hline Chicken & Intestinal loop & None & Akashi et al. (1993) \\
\hline Mouse & Intestinal loop & None & Fujii et al. (1995) \\
\hline
\end{tabular}

(b) In vitro assays

\begin{tabular}{|c|c|}
\hline Assay & Reference \\
\hline Radiolabelled DNA probe & $\begin{array}{l}\text { Lee } \text { et al. (1983) } \\
\text { Echeverria et al. (1984) } \\
\text { Moon } \text { et al. (1986) } \\
\text { Mainil et al. (1986, 1990) } \\
\text { Monckton \& Hasse (1988) } \\
\text { Woodward \& Wray (1990) } \\
\text { Lortie } \text { et al. (1991a, b) } \\
\text { Harel et al. (1991) } \\
\text { Handl et al. (1992) } \\
\text { Shin et al. (1994) } \\
\text { Nagy et al. (1990) }\end{array}$ \\
\hline Digoxigenin labelling of DNA & $\begin{array}{l}\text { Lortie et al. }(1991 \mathrm{c}) \\
\text { Boss et al. }(1992) \\
\text { Riley \& Caffrey }(1990)\end{array}$ \\
\hline Alkaline phosphatase labelling & Medon et al. (1988) \\
\hline PCR & Lortie et al. (1991c) \\
\hline Direct ELISA & $\begin{array}{l}\text { Urban et al. }(1990 \mathrm{a}) \\
\text { Dubreuil } \text { et al. }(1991) \\
\text { Lortie } \text { et al. }(1991 \mathrm{a}) \\
\text { Lawrence } \text { et al. }(1990)\end{array}$ \\
\hline Inhibition ELISA & $\begin{array}{l}\text { Handl et al. (1988) } \\
\text { Busque et al. (1995) }\end{array}$ \\
\hline Immunoblot & $\begin{array}{l}\text { Handl et al. (1988) } \\
\text { Bossé et al. (1993) }\end{array}$ \\
\hline Enhanced chemiluminescence immunodot & Lortie et al. (1991b) \\
\hline Ussing chambers & $\begin{array}{l}\text { Weikel et al. (1986c) } \\
\text { Whipp et al. (1987) } \\
\text { Hitotsubashi et al. (1992a) } \\
\text { Dreyfus et al. (1993) }\end{array}$ \\
\hline
\end{tabular}




\section{In vivo assays}

For many years, the only in vivo assay for STb was the pig intestinal loop assay (Smith \& Halls, 1967). The variability and inefficiency of this test for detection of the toxin was partly responsible for the fact that the STb toxin was only recently purified. In addition, this test was time-consuming and costly and could not be performed in every laboratory. Consequently, many epidemiological studies ignored the possible presence of STb.

It was not until Whipp (1987) showed that STb was susceptible to trypsin degradation and that variable amounts of trypsin-like activity in the swine jejunum were responsible for inconsistent responses to $\mathrm{STb}$, that other animal species were used to set up more reproducible, less expensive in vivo assays. His study suggested that the concept of species specificity of STb toxin, which had been widely accepted at that time, should be re-examined. It now seems that failure to demonstrate a response to $\mathrm{STb}$ in species other than the pig could reflect the presence of one or more intraluminal factors, such as, for example, intrinsic protease activity, which precluded a response. A subsequent study (Whipp, 1990) showed that STb evoked a dose-dependent secretory response in infant mice and jejunal loops of rats as long as endogenous protease activity was blocked with soybean trypsin inhibitor. Variation in sensitivity to $S T b$ was noted for different animal species. Thus, infant mice were much less sensitive to STb than rats and pigs. A secretory response was also observed in rabbits and calves (Whipp, 1991). Other researchers also established that the guinea-pig intestine (ileal loop) was sensitive to STb (Choudhry et al., 1991).

In addition to trypsin inhibitor (soybean) used by Whipp (1987), aprotinin, a serine protease inhibitor, has been used by Fujii et al. (1991) in a suckling mouse assay and in a mouse intestinal loop assay (Fujii et al., 1995) to render animals susceptible to STb. Unexpectedly, a mouse intestinal loop assay (Hitotsubashi et al., 1992b) and a chicken intestinal loop assay (Akashi et al., 1993) were shown to demonstrate $\mathrm{STb}$ activity without addition of protease inhibitor. Thus, it seems that protease inhibitors are not always essential for the observation of a response to STb enterotoxin, depending on the experimental protocol used. In general, these results indicated that the receptor for STb, if required, and the mechanism by which STb stimulates intestinal secretion, are present and functional in the intestinal mucosa of a variety of animal species. Thus, $\mathrm{STb}$ cannot be categorized as a pig-specific enterotoxin.

\section{In vitro assays}

A variety of in vitro assays have now been developed to evaluate the presence or absence of the STb gene or protein, and in some cases even to measure the amount of enterotoxin produced (Table 2).

In general, radiolabelled specific DNA fragments obtained from enterotoxin genes can be used as probes to detect homologous sequences in E. coli isolates. As the sequence of the gene encoding STb has been determined, the gene encoding STb may be detected using a specific DNA probe. The first report of the use of such a probe was in a molecular epidemiological study (Lee et al., 1983). The study indicated that a DNA fragment containing the $\mathrm{STb}$ gene was effectively specific in detecting STb-producers among clinical $E$. coli isolates. The use of radioactive probes has frequently been used by researchers for $\mathrm{STb}$ determination (Echeverria et al., 1984; Moon et al., 1986; Mainil et al., 1986, 1990; Monckton \& Hasse, 1988; Woodward \& Wray, 1990; Lortie et al., 1991a, b; Harel et al., 1991; Handl et al., 1992; Shin et al., 1994; Nagy et al., 1990). In general, these assays possess the advantage of being very specific and sensitive.

Non-radioactive DNA labelling techniques for the detection of the $\mathrm{STb}$ gene include digoxigenin labelling of DNA (Lortie et al., 1991c; Boss et al., 1992; Riley \& Caffrey, 1990) and alkaline phosphatase labelling (Medon et al., 1988). A simple PCR-based technique has also been developed (Lortie et al., 1991c).

In addition, antisera have been raised against $\mathrm{ST} b$, a poorly immunogenic molecule (Dubreuil et al., 1991), and a number of fusion proteins comprising $\mathrm{STb}$. These antibodies have been evaluated for their capacity to detect specifically the STb enterotoxin in numerous immunological tests. Thus, direct ELISA (Urban et al., 1990a; Dubreuil et al., 1991; Lortie et al., 1991a; Lawrence et al., 1990) and inhibition ELISA tests (Handl et al., 1988; Busque et al., 1995), immunoblot assays (Handl et al., 1988; Bossé et al., 1993) and an enhanced chemiluminescence immunodot assay (Lortie et al., 1991b) have been developed. Overall, the specificity and sensitivity of these immunologically based assays depended on the polyclonal antibodies used. Anti-STb monoclonal antibodies were developed by Urban $e t$ al. (1991) using a protein A-STb fusion protein as the immunogen and an $\mathrm{STb}$-alkaline phosphatase fusion protein to screen the clones. A total of four distinct anti$\mathrm{STb}$ antibodies were obtained and characterized.

Intestinal membranes of animals have been used to measure a short-circuit current in Ussing chambers. Different research teams showed that porcine ileal tissues responded electrogenically to $\mathrm{STb}$ enterotoxin (Weikel et al., 1986c; Whipp et al., 1987). Interestingly, human ileal tissue showed no response to $\mathrm{STb}$ in this in vitro test, suggesting that the adult human ileum may lack the receptor for STb. Some authors also used intestinal membranes to rule out, for $\mathrm{STb}$, known secretion mechanisms (Hitotsubashi et al., 1992a). Finally, cell cultures using cells of intestinal and nonintestinal origin were used by Dreyfus et al. (1993) to obtain information about the mechanism of action of STb.

\section{Genetic aspects - the estB gene}

Cloning and determination of the nucleotide sequence encoding STb was done independently (Lee et al., 1983; Picken et al., 1983). The gene encoding STb was referred 
to as est $A$ by different researchers (Mazaitis et al., 1981; Picken et al., 1983). This designation reflected the assumption that $\mathrm{STb}$ was one variant of $\mathrm{STa}$ enterotoxin. Today, this gene is referred to as est $B$ since the nucleotide and amino acid sequences of STb bear no relationship to STa.

The est $B$ gene that encodes $\mathrm{STb}$ is found on heterogeneous plasmids that may also determine other properties including other enterotoxins (i.e. LT, STa), colonization factors, drug resistance, colicin production and transfer functions (Harnett \& Gyles, 1985; Echeverria et al., 1985b). estB has been shown to be part of a transposon of approximately $9 \mathrm{~kb}$ designated Tn4521 (Lee et al., 1985; Hu et al., 1987; Hu \& Lee, 1988). This transposon is flanked by defective IS2 elements but is nevertheless functional as the STb gene can transpose from one plasmid to another (Lee et al., 1985; Hu \& Lee, 1988). The structural gene for STb from different clinical isolates appears to be uniform in size but the flanking sequences are heterogeneous suggesting that est $B$ could be found on different transposons (Lee et al., 1985). Thus it seems that transposition of $e s t B$ is a mechanism by which this virulence factor is disseminated among ETEC.

The est $B$ gene encodes a 71 amino acid polypeptide including a typical 23 amino acid signal peptide. Thus, mature STb polypeptide represents a 48 amino acid molecule. Final confirmation of the deduced amino acid sequence from the DNA came following purification and sequencing studies of the $\mathrm{STb}$ protein (Dreyfus et al., 1992).

Spandau \& Lee (1987) indicated that the promoter for est $B$ expression was weak. The promoter did not conform to the observed consensus sequence, as one important base in the Pribnow box $(-10$ region), the final invariant $\mathrm{T}$, is replaced by a $\mathrm{G}$. On the other hand, the -35 region is highly homologous to the -35 consensus sequence. Thus, the $\mathrm{STb}$ promoter is capable of binding RNA polymerase, but it is a poor initiator of transcription so very little $S T b$ is produced. Lawrence $e t$ al. (1990) indicated that cloning the est $B$ gene into a high-expression vector downstream to the strong bacteriophage lambda $p_{\mathrm{L}}$ promoter increased by $10-20$-fold the mRNA produced, but the amount of STb enterotoxin, as revealed by the bioassay, was not increased.

\section{STb polypeptide}

\section{Biochemical characteristics}

The $\mathrm{STb}$ polypeptide is synthesized as a 71 amino acid precursor (Lee et al., 1983, Picken et al., 1983). The $\mathrm{NH}_{2}$-terminus of pro-STb (residues 1-23) has characteristics of a signal sequence that is cleaved, presumably by a signal peptidase, during export to the periplasm, and the periplasmic STb is then translocated to the extracellular medium (Kupersztoch et al., 1990). Mature $\mathrm{STb}$ is a 48 amino acid peptide containing 4 cysteine residues. Disulfide bridges exist between Cys-33 and
Cys-71, and between Cys-44 and Cys-59 (Fujii et al., 1991) (Fig. 1). STb bears no homology to STa enterotoxin (Dreyfus et al., 1992). It loses biological activity upon $\beta$-mercaptoethanol or trypsin treatment (Dubreuil et al., 1991; Fujii et al., 1991). Out of 48 residues, the mature toxin contains only one tyrosine, two phenylalanine and no tryptophan residues, explaining the low absorbance at $280 \mathrm{~nm}$ (Handl et al., 1993). The determined isoelectric point of $9 \cdot 6$ corresponds to a highly basic protein (Handl et al., 1993). Purified STb is poorly immunogenic when injected into rabbits as numerous booster doses were required to obtain a significant antibody titre and the resulting polyclonal antiserum was non-neutralizing (Dubreuil et al., 1991). However, use of a fusion protein containing STb resulted in increased immunogenicity (Dubreuil et al., 1996) and neutralizing antisera were raised.

\section{Production characteristics}

$\mathrm{STb}$ is not associated with the cellular fraction but found preferentially in the culture supernatant (Kupersztoch et al., 1990). Many studies have reported poor yield of toxin from wild-type strains (Urban et al., 1990b; Dubreuil et al., 1991). The production of STb by wild-type E. coli strains was recently studied using a quantitative STb-specific inhibition ELISA (Busque et al., 1995). Variation was found between the wild-type strains and the production also varied with the liquid culture medium used. Thus, STb production is controlled by growth conditions. A repressive effect of glucose on STb production and a reversal of this effect upon addition of cAMP was observed. Catabolite repression of $\mathrm{STb}$ was confirmed using mutant strains for adenylate cyclase and catabolite activator protein. A DNA homology search revealed a sequence with $72 \%$ identity with the cAMP receptor protein (CRP)-binding site located 26 bp upstream of the -35 region of the transcriptional start site of estB.

\section{Purification of STb}

Purification of $S T \mathrm{~b}$, as stated before, has been hampered due to the low levels of toxin produced by wild-type $E$. coli strains and the lack of a convenient in vitro assay. Nevertheless, native STb has been purified from a wildtype strain (Dubreuil et al., 1991) and from strains carrying a recombinant plasmid (Fujii et al., 1991; Dreyfus et al., 1992). Studies describing purification from a cloned hybrid fusion protein, where STb could be cleaved and purified to homogeneity, were reported by Bossé et al. (1993) and Handl et al. (1993).

\section{Secretion and disulfide bond formation}

For conversion into active $\mathrm{STb}$, the intramolecular bonds must be correctly formed. The pathways by which these bonds are formed have been established. Kupersztoch et al. (1990) showed that STb is a 48 amino acid molecule corresponding to a $5 \cdot 2 \mathrm{kDa}$ extracellular 


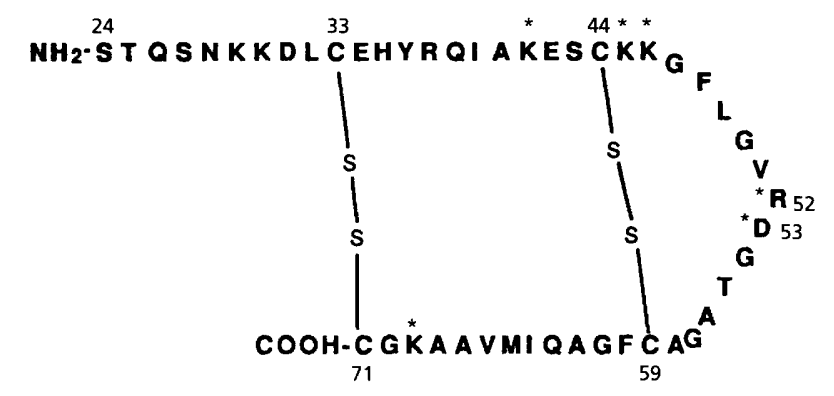

Fig. 1. Amino acid sequence of mature STb. The sequence is numbered taking into account the first 23 amino acids residues representing the signal sequence. Note the position of the disulfide bridges between Cys-33 and Cys-71, and Cys-44 and Cys-59. Asterisks indicate residues shown to be important for STb toxicity.

polypeptide. This molecule is a transient periplasmic species and a single processing event on a precursor results in it becoming extracellular. Thus, an $8.1 \mathrm{kDa}$ precursor (pre-STb) is converted to a transiently cellassociated $5 \cdot 2 \mathrm{kDa}$ form. After STb is detected as a cellassociated molecule, an indistinguishable extracellular form becomes apparent, suggesting that no proteolytic processing occurs during mobilization of STb from the periplasm to the culture supernatant. Conversion of cellular to extracellular STb does not depend on membrane potential or oxidative phosphorylation. Conversion of pre-STb to cellular STb depends on the secA gene product. For $\mathrm{STb}$, like STa, translocation of the precursor to the periplasm requires energy (Kupersztoch et al., 1990). These data indicate that export of STb relies on the general export pathway of E. coli.

Foreman et al. (1995) obtained secretion-deficient mutants using a synthetic transposon. In $d s b A$ and tolC mutants, STb was absent from the culture supernatant indicating that these genes were required for secretion of $\mathrm{STb}$. Mutations in tolC and $d s b A$ produced a $\mathrm{STb}^{-}$ phenotype because the precursors did not cross the outer membrane after they had reached the periplasm; instead they were periplasmically degraded.

Concerning disulfide bond formation, Dreyfus et al. (1992) explored the role of the four cysteine residues in STb secretion. Cys-44 and Cys-71 were separately substituted with serine residues. The resulting peptides were exported to and degraded in the periplasm, suggesting that formation of disulfide bridges protected STb, a lysine (6) and arginine (2) containing peptide, from a trypsin-like activity. Therefore, as observed by Foreman et al. (1995), a dsbA mutant forming disulfide bridges at a slower rate yielded a $\mathrm{STb}^{-}$phenotype as the reduced form was degraded. Similarly, Okamoto et al. (1995) transformed a $d s b A$ mutant with a plasmid harbouring est $B ; \mathrm{STb}$ was not detected either in the cells or in the culture supernatant. In this study, STb production was shown to be restored by introducing the wild-type $d s b A$ gene into the mutant strain. Thus, it was confirmed that $d s b A$ is involved in forming the disulfide bonds in $\mathrm{ST}$ b and that its absence resulted in degradation of STb during secretion. Using oligonucleotide-directed site-specific mutagenesis of the four cysteine residues it was established by Arriaga et al. (1995) that the two intramolecular disulfide bonds must be formed for the efficient secretion of STb. Elimination of either one of the bonds renders the toxin susceptible to periplasmic proteolysis and abolishes its toxicity.

\section{Residues related to toxicity and structure determination}

As the isoelectric point of $9 \cdot 6$ indicates, the side-chain of some of the basic amino acid residues project outside the $\mathrm{STb}$ molecule. Some studies have been conducted to determine the role of selected amino acids, and in particular of the basic residues, on the toxicity of STb. Among the 48 amino acids composing STb, 9 are basic (1 His, 2 Arg and 6 Lys).

A loop defined by the disulfide bond between Cys-44 and Cys-59 containing 14 amino acids (Fig. 1), including four Gly residues and four of the charged residues based on secondary structure predictions, suggested the presence of an extended coil region (Dreyfus et al., 1992). The location of a Arg-52 and Asp-53 charged pair inside this loop is such that it could be highly exposed in a hydrophilic environment and the authors speculated that it would probably be involved in receptor recognition. Using site-directed mutagenesis, substitutions were performed on these two residues. When Arg-52 was changed to Ser to eliminate the charge, a significant reduction in specific activity of the mutant molecule was noted, a smaller reduction of toxicity was associated with the substitution of Asp-53. No reduction in stability of the altered molecule was noted in the intestinal loop model. The mutated toxins (Ser replacing the charged amino acids) did not interfere with the toxic activity of native $S T b$, suggesting that they were not competing for the putative STb receptor.

Fujii et al. (1994) likewise investigated the role of basic amino acid residues on $\mathrm{STb}$ enterotoxicity. Studies involving chemically modified $\mathrm{STb}$ indicated that Lys residues play an important role in STb toxicity and that the contribution of other basic residues to toxicity is relatively low. These results were confirmed using oligonucleotide-directed mutagenesis. When Lys residues at positions $41,45,46$ and 69 were replaced by neutral amino acids, the toxicity of the molecule was reduced. Changes of Lys-45 and Lys-46 resulted in a considerable reduction in toxicity.

Sukumar et al. (1995) determined the solution structure of STb by two- and three-dimensional NMR methods. The NMR-derived structure showed that STb is helical between residues 33 and 46 and residues 61 and 67 . The helical structure in the region 33-46 is amphipathic and exposes several polar residues to the solvent, some of which have been shown to be important in toxicity. The loop region between residues 44 and 59 contains a cluster of hydrophobic residues and exposes Arg-52 and Asp-53. These residues, as discussed before, are important in toxicity. Circular dichroism studies indicated 
that the integrity of the disulfide bridges is crucial for the structure and function of the toxin as reduced $\mathrm{STb}$ adopted a random coiled conformation. STb is thus a highly organized molecule with $73 \pm 2 \%$ helix, $4 \pm 2 \%$ $\beta$-structure and $22 \%$ remainder. Overall, the results indicated that the peptide spanning the region from Cys33 to Cys-71 has full activity and that the peptide consisting of the first 7 amino acids at the $\mathrm{NH}_{2}$-terminus is not involved in either the structure or toxicity of STb. This characteristic was also observed for STa (Gariépy et al., 1986).

\section{Mechanism of action}

Initial studies to determine the mechanism of action of $\mathrm{STb}$ were performed with crude culture filtrates of $\mathrm{STb}^{+}$ ETEC strains. Kennedy et al. (1984) first reported that $\mathrm{STb}$ induced fluid secretion after $3-6 \mathrm{~h}$ and that the toxin did not disrupt intestinal histology. STb stimulated cyclic-nucleotide-independent secretion. Thus, STb appeared as a cytotonic toxin with properties and a mechanism of action differing from STa. Using Ussing chambers and crude culture filtrate containing STb, W/eikel \& Guerrant (1985) showed that the toxin promptly increased the short circuit current and potential difference. The toxin did not alter unidirectional or net fluxes of ${ }^{22} \mathrm{Na}$ or ${ }^{36} \mathrm{Cl}$ when tested in bidirectional in vitro studies. Relative to controls, significant accumulation of $\mathrm{Na}$ and $\mathrm{Cl}$ occurred intraluminally in vivo. Measurements of the electrolyte content of ligated intestinal segments in vivo further suggested that $\mathrm{STb}$ stimulated bicarbonate secretion (Fig. 2).

Whipp et al. (1985) observed that a virus-induced loss of villous epithelium resulted in an absence of response to $\mathrm{STb}$. The secretory response of STb thus seemed to be dependent on the integrity of the villous epithelium. Contradictory observations were reported in different studies. For example, Whipp et al. (1986) observed that exposure of swine jejunum to a culture supernatant containing STb induced microscopic alterations of intestinal mucosa, in particular the loss of villous absorptive cells and partial atrophy of villi, which are consistent with the loss of absorptive capacity. The toxin was capable of causing partial villous atrophy in pigs after only $2 \mathrm{~h}$ (Whipp et al., 1987; Rose et al., 1987). Using light microscopy, Hitotsubashi et al. (1992b) observed that exposure of the mouse jejunum to purified $\mathrm{STb}$ for $3 \mathrm{~h}$ caused a dilation of capillaries of the submucosa and a decrease in the thickness of the lamina propria. No cellular damage or inflammation was observed. Thus, it appeared that damage to the epithelium occurred when culture supernatant containing $\mathrm{S} T \mathrm{~b}$, but not the purified toxin, was used.

Using a mouse intestinal loop assay and purified toxin, Hitotsubashi et al. (1992b) confirmed that STb did not alter cGMP or cAMP levels in intestinal mucosal cells, thus indicating that the mechanism of action of STb in inducing fluid secretion differs from that of $\mathrm{STa}$ and cholera toxin (CT). The level of prostaglandin $\mathrm{E}_{2}\left(\mathrm{PGE}_{2}\right)$ in the fluid increased as a result of STb action and prostaglandin synthesis inhibitors such as aspirin and indomethacin significantly reduced the response to $\mathrm{STb}$. This report was the first to implicate $\mathrm{PGE}_{2}$ in the mechanism of action of STb. CT was previously shown to increase $\mathrm{PGE}_{1}$ and $\mathrm{PGE}_{2}$ contents in the intestinal tissues of rabbits, indicating that prostaglandins may regulate water and electrolytes in cholera (Peterson \& Ochoa, 1989). A histopathological study indicated that $\mathrm{STb}$ increased the blood volume resulting in dilation of capillaries. Thus, PGE $_{2}$ levels are involved in the onset of diarrhoea in intestinal mucosal cells. Although intraluminally administered $\mathrm{PGE}_{2}$ is known to induce duodenal and jejunal secretion of water and of electrolytes such as $\mathrm{Cl}^{-}$and $\mathrm{Na}^{+}$(Rask-Madsen \& Bukhave, 1981), the precise mechanism by which these secretions are induced is not yet known.

More recently, Fujii et al. (1995) confirmed that the quantity of $\mathrm{PGE}_{2}$ produced by intestinal cells was directly related to the dose of $\mathrm{STb}$ administered to the mouse. In addition, the quantity of $\mathrm{PGE}_{2}$ correlated with the volume of fluid released into the intestinal lumen. Levels of arachidonic acid and phosphatidic acid were also elevated by $\mathrm{STb}$, indicating that arachidonic acid metabolism is stimulated by STb.

Two groups have independently reported that both $\mathrm{PGE}_{2}$ and 5-hydroxytryptamine (5-HT), the latter being regarded as another secretagogue, were released into the intestinal fluid (Harville \& Dreyfus, 1995; Peterson \& Whipp, 1995). Peterson \& Whipp (1995) compared the secretory effects of $\mathrm{CT}, \mathrm{STa}$ and $\mathrm{STb}$ using the pig intestinal loop model and measured the effects of those toxins on the synthesis of cAMP, cGMP and $\mathrm{PGE}_{2}$ as well as the release of 5-HT from intestinal enterochromaffin cells. A combination of maximal doses of $\mathrm{STa}$ and $\mathrm{ST} b$ yielded additive effects on fluid accumulation, suggesting different mechanisms of action. A similar additive effect on fluid accumulation and luminal release of 5-HT was noted with a combination of CT and STb. A cAMP response to STb could not be demonstrated in either mucosal tissue or luminal fluid. Thus, it appears that the mechanisms of action of STb and CT are distinct. Treatment of rats with ketanserin, a 5-HT receptor antagonist, reduced intestinal secretion induced by STb (Harville \& Dreyfus, 1995). Nonetheless, the mode of action of STb may be similar to that of CT since the latter toxin stimulates the release of both $\mathrm{PGE}_{2}$ and 5-HT, suggesting a potential effect on the enteric nervous system. Interestingly, a study by Eklund et al. (1985) using an E. coli strain producing both STa and $\mathrm{STb}$ showed that, at least in rats and cats, these heat-stable enterotoxins evoke secretion in part via activation of the enteric nervous system. Drugs influencing nervous activity, such as lidocaine, tetrodotoxin and atropine, significantly diminished the secretory response. Furthermore, a study using isolated mouse ileum indicated that $\mathrm{STb}$ could also act directly on the muscle cells of the ileal serosa increasing the spontaneous motility of the intestine and resulting in contractions (Hitotsubashi et al., 1992a). These contractions were not induced when the toxin was applied to 

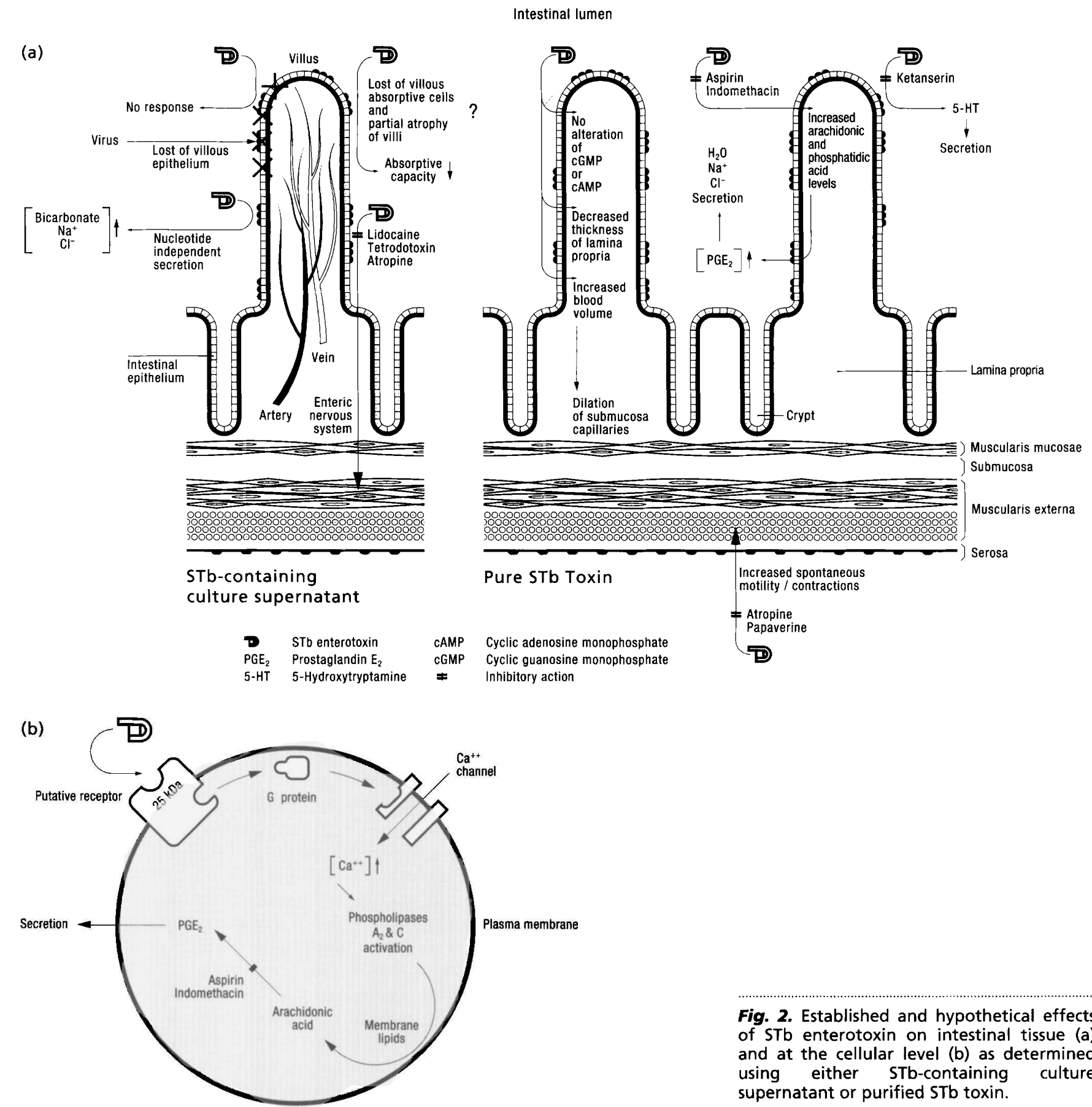

Fig. 2. Established and hypothetical effects of STb enterotoxin on intestinal tissue (a) and at the cellular level (b) as determined using either STb-containing culture supernatant or purified STb toxin.

the mucosa. The spontaneous motility was inhibited by atropine, indicating that it was not the result of the excitation of cholinergic nerves. Papaverine, which causes relaxation of smooth muscle, had an inhibitory effect on $\mathrm{STb}$, implying that $\mathrm{STb}$ acts directly on muscle cells.

An in vitro study suggested that $\mathrm{STb}$ functions by opening a G-protein-linked, receptor-operated calcium channel in the plasma membrane (Dreyfus et al., 1993). A dose-dependent increase in intracellular $\mathrm{Ca}^{2+}$ that was linked to extracellular $\mathrm{Ca}^{2+}$ was observed. This process could be blocked by agents that impair GTP-binding regulatory function. Elevated intracellular $\mathrm{Ca}^{2+}$ activates both phospholipase A2 and phospholipase C, two important enzymes for the release of arachidonic acid from membrane lipids (Dunlop \& Larkins, 1984). It thus appears that the initial action of STb in the induction of diarrhoea is the uptake of $\mathrm{Ca}^{2+}$ into cells. Subsequently, synthesis of $\mathrm{PGE}_{2}$ and other secretagogues is stimulated, leading to the induction of diarrhoea.

\section{Receptor identification}

Hitotsubashi et al. (1994) identified a protein of $25 \mathrm{kDa}$ from the cell membranes of mouse intestine that binds to 
STb. The specificity of the interaction was corroborated by competition experiments between radiolabelled $\left({ }^{125} \mathrm{I}\right)$ and unlabelled toxin. Preliminary characterization of the molecule suggested that it was not a glycoprotein as it did not bind to concanavalin A-Sepharose nor was it digested with endo- $\beta$-glycosidase $\mathrm{H}$ as observed by SDSPAGE. This study also indicated tissue specificity as the STb-binding protein was not found in mouse tissues such as liver, lung, spleen and kidney. No lesions were evident in any organs following visual inspection after STb has been administered intravenously at $1 \mathrm{mg}$ per mouse. Surprisingly, Dreyfus et al. (1993) inferred from an in vitro study that the $\mathrm{STb}$ receptor is present on cell types of both intestinal and non-intestinal origin, as Madin-Darby canine kidney, HT- $29 / \mathrm{C}_{1}$ intestinal epithelial cells and primary rat pituitary cells all responded to STb. In all these cell types, a dose-dependent increase in calcium concentration due to STb action was noted.

A study by Weikel et al. (1986b) examining the response in a Ussing chamber of human adult ileal mucosa to STb clearly indicated that, in contrast to the piglet jejunum which responded electrogenically to $\mathrm{STb}$, human tissue showed no response. From their work, they inferred that the adult human ileum could lack the receptor for STb. With the present state of knowledge, it is difficult to understand the discrepencies between the different studies on the STb receptor.

\section{Perspective}

The recent purification of STb enterotoxin has helped to clarify some biochemical and mechanistic aspects of this toxin. Mutagenesis experiments have contributed to defining reactive sites on the polypeptide and threedimensional structure determination will be needed to understand more fully the toxin-receptor interaction when the receptor has been definitively identified. A more thorough investigation of the mechanism of action of $\mathrm{STb}$ is crucial for our understanding of the pathogenesis of diarrhoeal illness and to devise effective therapeutic strategies which could interfere with the secretory pathways.

Finally, the study of the STb toxin may have suffered from being originally considered as a pig-specific toxin. However, now that at least some human E. coli strains producing STb have been isolated, although not directly related to diarrhoea in man, a new interest in this enterotoxin may be generated in the coming years.

\section{Acknowledgements}

The author is supported by grants from the Natural Sciences and Engineering Research Council of Canada (OGPO139070) and 'Fonds pour la formation de chercheurs et l'Aide à la recherche (93-ER-0214)'. The author acknowledges T. Gendron-Bernard for typing the manuscript, J. Harel, J. M. Fairbrother and E. Rousset for their suggestions, and $M$. Bhérer for his help with histological terminology.

\section{References}

Akashi, N., Hitotsubashi, S., Yamanaka, H., Fujii, Y., Tsuji, T., Miyama, A., Encarnacion Joya, J. \& Okamoto, K. (1993). Production of heat-stable enterotoxin II by chicken clinical isolates of Escherichia coli. FEMS Microbiol Lett 109, 311-316.

Arriaga, Y. L., Harville, B. A. \& Dreyfus, L. A. (1995). Contribution of individual disulfide bonds to biological action of Escherichia coli heat-stable enterotoxin B. Infect Immun 63, 4715-4720.

Betley, M. J., Miller, V. L. \& Mekalanos, J. J. (1986). Genetics of bacterial enterotoxins. Annu Rev Microbiol 40, 577-605.

Boss, P., Monckton, R. P., Nicolet, J. \& Burnens, A.P. (1992). Nachweis von toxingenen verschiedener $E$. coli pathotypen beim schwein mit nichtradioaktiv markierten sonden. Schweiz Arch Tierbeilkd 134, 31-37.

Bossé, M., Handl, C. E., Lortie, L.-A., Harel, J. \& Dubreuil, J. D. (1993). Fusion of the genes encoding Escherichia coli heat-stable enterotoxin $\mathrm{b}(\mathrm{STb})$ and the maltose-binding protein to obtain mature STb enterotoxin. J Gen Microbiol 139, 631-638.

Burgess, M. N., Bywater, R. J., Cowley, C. M., Mullan, N. A. \& Newsome, P. M. (1978). Biological evaluation of a methanolsoluble, heat-stable Escherichia coli enterotoxin in infant mice, pigs, rabbits, and calves. Infect Immun 21, 526-531.

Busque, P., Letellier, A., Harel, J. \& Dubreuil, J. D. (1995). Production of Escherichia coli STb enterotoxin is subject to catabolite repression. Microbiology 141, 1621-1627.

de Castro, A. F. P., Gatti, M. S. V., Serafim, M. B., Brito, J. R. F. \& Barcellos, D. S. E. N. (1984). Significance of thermostable enterotoxin produced by porcine enteropathogenic Escherichia coli. Vet Rec 115, 518-519.

Choudhry, M. A., Gupta, S. \& Yadava, J. N. S. (1991). Guinea-pig ileal loop assay: a better replacement of the suckling mouse assay for detection of heat-stable enterotoxins of Escherichia coli. J Trop Med Hyg 94, 234-240.

Dreyfus, L. A., Urban, R. G., Whipp, S. C., Slaughter, C., Tachias, K. \& Kupersztoch, Y. M. (1992). Purification of the $S_{B}$ enterotoxin of Escherichia coli and the role of selected amino-acids on its secretion, stability and toxicity. Mol Microbiol 6, 2397-2406.

Dreyfus, L. A., Harville, B., Howard, D. E., Shaban, R., Beatty, D. M. \& Morris, S. J. (1993). Calcium influx mediated by the Escherichia coli heat-stable enterotoxin $\mathrm{B}\left(\mathrm{ST}_{\mathrm{B}}\right)$. Proc Natl Acad Sci USA 90, 3202-3206.

Dubreuil, J. D., Fairbrother, J. M., Lallier, R. \& Larivière, S. (1991). Production and purification of heat-stable enterotoxin $b$ from a porcine Escherichia coli strain. Infect Immun 59, 198-203.

Dubreuil, J. D., Letellier, A. \& Harel, J. (1996). A recombinant Escherichia coli heat-stable enterotoxin b (STb) fusion protein eliciting neutralizing antibodies. FEMS Immunol Med Microbiol 13, 317-323.

Dunlop, M. E. \& Larkins, R. G. (1984). Activity of endogenous phospholipase $\mathrm{C}$ and phospholipase $\mathrm{A}_{2}$ in glucose stimulated pancreatic islets. Biochem Biophys Res Commun 120, 820-827.

Echeverria, P., Seriwatana, J., Patamaroj, U., Moseley, S. L., McFarland, A., Chityothin, O. \& Chaicumpa, W. (1984). Prevalence of heat-stable II enterotoxigenic Escherichia coli in pigs, water, and people at farms in Thailand as determined by DNA hybridization. J Clin Microbiol 19, 489-491.

Echeverria, P., Seriwatana, J., Taylor, D. N., Tirapat, C., Chaicumpa, W. \& Rowe, B. (1985a). Identification by DNA hybridization of enterotoxigenic Escherichia coli in a longitudinal study of villages in Thailand. J Infect Dis 151, 124-130. 
Echeverria, P., Seriwatana, J., Taylor, D. N., Tirapat, C. \& Rowe, B. (1985b). Escherichia coli contains plasmids coding for heat-stable $\mathrm{b}$, other enterotoxins, and antibiotic resistance. Infect Immun 48 , 843-846.

Eklund, S., Jodal, M. \& Lundgren, O. (1985). The enteric nervous system participates in the secretory response to the heat stable enterotoxins of Escherichia coli in rats and cats. Neuroscience 14, 673-681.

Fairbrother, J. M., Larivière, S. \& Johnson, W. M. (1988). Prevalence of fimbriae antigens and enterotoxins in nonclassical serogroups of Escherichia coli isolated from newborn pigs with diarrhea. Am J Vet Res 49, 1325-1328.

Fairbrother, J. M., Broes, A., Jacques, M. \& Larivière, S. (1989). Pathogenicity of Escherichia coli O115:K 'V165' strains isolated from pigs with diarrhea. Am J Vet Res 50, 1029-1036.

Foreman, D. T., Martinez, Y., Coombs, G., Torres, A. \& Kupersztoch, Y. M. (1995). TolC and DsbA are needed for the secretion of $\mathrm{ST}_{\mathrm{B}}$, a heat-stable enterotoxin of Escherichia coli. Mol Microbiol 18, 237-245.

Fujii, Y., Hayashi, M., Hitotsubashi, S., Fuke, Y., Yamanaka, H. \& Okamoto, K. (1991). Purification and characterization of Escherichia coli heat-stable enterotoxin II. J Bacteriol 173, 5516-5522.

Fujii, Y., Okamuro, Y., Hitotsubashi, S., Saito, A., Akashi, N. \& Okamoto, K. (1994). Effects of alterations of basic amino acid residues of Escherichia coli heat-stable enterotoxin II on enterotoxicity. Infect Immun 62, 2295-2301.

Fujii, Y., Kondo, Y. \& Okamoto, K. (1995). Involvement of prostaglandin $E_{2}$ synthesis in the intestinal secretory action of Escherichia coli heat-stable enterotoxin II. FEMS Microbiol Lett 130, 259-266.

Gariépy, J., Lane, A., Frayman, F., Wilbur, D., Robien, W., Schoolnik, G. K. \& Jardetzki, O. (1986). Structure of the toxin domain of Escherichia coli heat-stable enterotoxin STI. Biochemistry 25, 7854-7866.

Gyles, C. L. (1994). Escherichia coli enterotoxins. In Escherichia coli in Domestic Animals and Humans, pp. 337-364. Edited by C. L. Gyles. Wallingford, UK: CAB International.

Handl, C. E. \& Flock, J.-I. (1992). STb producing Escherichia coli are rarely associated with infantile diarrhoea. J Diarrhoeal Dis Res 10, 37-38.

Handl, C., Rönnberg, B., Nilsson, B., Olsson, E., Jonsson, H. \& Flock, J.-I. (1988). Enzyme-linked immunosorbent assay for Escherichia coli heat-stable enterotoxin type II. J Clin Microbiol 26, 1555-1560.

Handl, C. E., Olsson, E. \& Flock, J.-I. (1992). Evaluation of three different $\mathrm{STb}$ assays and comparison of enterotoxin pattern over a five-year period in swedish porcine Escherichia coli. Diagn Microbiol Infect Dis 15, 505-510.

Handl, C. E., Harel, J., Flock, J.-I. \& Dubreuil, J. D. (1993). High yield of active STb enterotoxin from a fusion protein (MBP-STb) expressed in Escherichia coli. Protein Expr Purif 4, 275-281.

Harel, J., Lapointe, H., Fallara, A., Lortie, L.-A., Bigras-Poulin, M., Larivière, S. \& Fairbrother, J. M. (1991). Detection of genes for fimbrial antigens and enterotoxins associated with Escherichia coli serogroups isolated from pigs with diarrhea. J Clin Microbiol 29, 745-752.

Harnett, N. M. \& Gyles, C. L. (1985). Linkage of genes for heatstable enterotoxin, drug resistance, K99 antigen, and colicin in bovine and porcine strains of enterotoxigenic Escherichia coli. Am J Vet Res 46, 428-433.
Harville, B. A. \& Dreyfus, L. A. (1995). Involvement of 5-hydroxytryptamine and prostaglandin $E_{2}$ in intestinal secretory action of Escherichia coli heat-stable enterotoxin B. Infect Immun 63, $745-750$.

Hitotsubashi, S., Akagi, M., Saitou, A., Yamanaka, H., Fujii, Y. \& Okamoto, K. (1992a). Action of Escherichia coli heat-stable enterotoxin II on isolated sections of mouse ileum. FEMS Microbiol Lett 90, 249-252.

Hitotsubashi, S., Fujii, Y., Yamanaka, H. \& Okamoto, K. (1992b). Some properties of purified Escherichia coli heat-stable enterotoxin II. Infect Immun 60, 4468-4474.

Hitotsubashi, S., Fujii, Y. \& Okamoto, K. (1994). Binding protein for Escherichia coli heat-stable enterotoxin II in mouse intestinal membrane. FEMS Microbiol Lett 122, 297-302.

Hu, S. T. \& Lee, C. H. (1988). Characterization of the transposon carrying the STII gene of enterotoxigenic Escherichia coli. Mol Gen Genet 214, 490-495.

Hu, S. T., Yang, M. K., Spandau, D. F. \& Lee, C. H. (1987). Characterization of the terminal sequences flanking the transposon that carries the Escherichia coli enterotoxin STII gene. Gene 55, 157-167.

Kennan, R. M. \& Monckton, R.P. (1990). Adhesive fimbriae associated with porcine enterotoxigenic Escherichia coli of the O141 serotype. J Clin Microbiol 28, 2006-2011.

Kennedy, D. J., Greenberg, R. N., Dunn, J. A., Abernathy, R., Ryerse, J. S. \& Guerrant, R. L. (1984). Effects of Escherichia coli heat-stable enterotoxin STb on intestines of mice, rats, rabbits, and piglets. Infect Immun 46, 639-643.

Kupersztoch, Y. M., Tachias, K., Moomaw, C. R., Dreyfus, L. A., Urban, R., Slaughter, C. \& Whipp, S. C. (1990). Secretion of a methanol-insoluble heat-stable enterotoxin $\left(\mathrm{ST}_{\mathrm{B}}\right)$ : energy- and sec- $A$ dependent conversion of pre- $\mathrm{ST}_{\mathrm{B}}$ to an intermediate indistinguishable from the extracellular toxin. J Bacteriol 172 , 2427-2432.

Lawrence, R. M., Huang, P.-T., Glick, J., Oppenheim, J. D. \& Maas, W. K. (1990). Expression of the cloned gene for enterotoxin $S T b$ of Escherichia coli. Infect Immun 58, 970-977.

Lee, C. H., Moseley, S. L., Moon, H. W., Whipp, S. C., Gyles, C. L. \& So, M. (1983). Characterization of the gene encoding heat-stable toxin II and preliminary molecular epidemiological studies of enterotoxigenic Escherichia coli heat-stable toxin II producers. Infect Immun 42, 264-268.

Lee, C. H., Hu, S. T., Swiatek, P. J., Moseley, S. L., Allen, S. D. \& So, M. (1985). Isolation of a novel transposon which carries the Escherichia coli enterotoxin STII gene. J Bacteriol 162, 615-620.

Li, J. (1992). Bacterial toxins. Curr Opin Struct Biol 2, 545-556.

Lortie, L.-A., Harel, J., Fairbrother, J. M. \& Dubreuil, J. D. (1991a). Evaluation of three new techniques for the detection of STbpositive Escherichia coli strains. Mol Cell Probes 5, 271-275.

Lortie, L.-A., Harel, J., Fairbrother, J. M. \& Dubreuil, J. D. (1991b). Immunodot detection of Escherichia coli heat-stable enterotoxin b by using enhanced chemiluminescence reaction. J Clin Microbiol 29, 2250-2252.

Lortie, L.-A., Dubreuil, J. D. \& Harel, J. (1991c). Characterization of Escherichia coli strains producing heat-stable enterotoxin b (STb) isolated from humans with diarrhea. J Clin Microbiol 29, 656-659.

Mainil, J., Moseley, S. L., Schneider, R. A., Sutch, K., Casey, T. A. \& Moon, H. W. (1986). Hybridization of bovine Escherichia coli isolates with gene probes for four enterotoxins $(S T a P, S T a H$, $\mathrm{STb}, \mathrm{LT}$ ) and one adhesion factor (K99). Am J Vet Res 47, $1145-1148$. 
Mainil, J. G., Bex, F., Jacquemin, E., Pohl, P., Couturier, M. \& Kaeckenbeeck, A. (1990). Prevalence of four enterotoxin (STaP, $\mathrm{STaH}, \mathrm{STb}$ and LT) and four adhesin subunit (K99, K88, 987P, and F41) genes among Escherichia coli isolates from cattle. Am J Vet Res 51, 187-190.

Mazaitis, A. J., Maas, R. \& Maas, W. K. (1981). Structure of a naturally occuring plasmid with genes for enterotoxin production and drug resistance. J Bacteriol 145, 97-105.

Medon, P. P., Lanser, J. A., Monckton, P. R., Li, P. \& Symons, R. H. (1988). Identification of enterotoxigenic Escherichia coli isolates with enzyme-labeled synthetic oligonucleotide probes. J Clin Microbiol 26, 2173-2176.

Monckton, R. P. \& Hasse, D. (1988). Detection of enterotoxigenic Escherichia coli in piggeries in Victoria by DNA hybridisation using K88, K99, LT, ST 1 and $\mathrm{ST}_{2}$ probes. Vet Microbiol 16, 273-281.

Moon, H. W., Kohler, E. M., Schneider, R. A. \& Whipp, S. C. (1980). Prevalence of pilus antigens, enterotoxin types, and enteropathogenicity among K88-negative enterotoxigenic Escherichia coli from neonatal pigs. Infect Immun 27, 222-230.

Moon, H. W., Schneider, R. A. \& Moseley, S. L. (1986). Comparative prevalence of four enterotoxin genes among Escherichia coli isolated from swine. Am J Vet Res 47, 210-212.

Nagy, B., Casey, T. A. \& Moon, H. W. (1990). Phenotype and genotype of Escherichia coli isolated from pigs with postweaning diarrhea in Hungary. J Clin Microbiol 28, 651-653.

Okamoto, K., Fujii, Y., Akashi, N., Hitotsubashi, S., Kurazono, H., Karasawa, T. \& Takeda, Y. (1993). Identification and characterization of heat-stable enterotoxin II-producing Escherichia coli from patients with diarrhea. Microbiol Immunol 37, 411-414.

Okamoto, K., Baba, T., Yamanaka, H., Akashi, N. \& Fujii, Y. (1995). Disulfide bond formation and secretion of Escherichia coli heatstable enterotoxin II. J Bacteriol 177, 4579-4586.

Osek, J. \& Truszczynski, M. (1992). Occurrence of fimbriae and enterotoxins in Escherichia coli strains isolated from piglets in Poland. Comp Immunol Microbiol Infect Dis 15, 285-292.

Peterson, J. W. \& Ochoa, L. G. (1989). Role of prostaglandins and cAMP in the secretory effects of cholera toxin. Science 245, 857-859.

Peterson, J.W. \& Whipp, S.C. (1995). Comparison of the mechanisms of action of cholera toxin and the heat-stable enterotoxins of Escherichia coli. Infect Immun 63, 1452-1461.

Picken, R. N., Mazaitis, A. J., Maas, W. K., Rey, M. \& Heyneker, H. (1983). Nucleotide sequence of the gene for heat-stable enterotoxin II of Escherichia coli. Infect Immun 42, 269-275.

Rask-Madsen, J. \& Bukhave, K. (1981). The role of prostaglandins in diarrhea. In Diarrhea: New Insights, pp. 58-70. Edited by N. W'. Read. London: Janssen Pharmaceutical.

Riley, L. K. \& Caffrey, C. J. (1990). Identification of enterotoxigenic Escherichia coli by colony hybridization with nonradioactive digoxigenin-labeled DNA probes. J Clin Microbiol 28, 1465-1468.

Rose, R., Whipp, S. C. \& Moon, H. W. (1987). Effects of Escherichia coli heat-stable enterotoxin b on small intestinal villi in pigs, rabbits, and lambs. Vet Pathol 24, 71-79.

Sears, C. L. \& Kaper, J. B. (1996). Enteric bacterial toxins: mechanisms of action and linkage to intestinal secretion. Microbiol Rev 60, 167-215.

Shin, S. J., Chang, Y.-F., Timour, M., Lauderdale, T.-L. \& Lein, D. H. (1994). Hybridization of clinical Escherichia coli isolates from calves and piglets in New York state with gene probes for enterotoxins (STaP, STb, LT), shiga-like toxins (SLT-1, SLT-II) and adhesion factors (K88, K99, F41, 987P). Vet Microbiol 38, 217-225.

Smith, H. W. \& Gyles, C. L. (1970). The relationship between two apparently different enterotoxins produced by enteropathogenic strains of Escherichia coli of porcine origin. J Med Microbiol 3, $387-401$.

Smith, H. W. \& Halls, S. (1967). Observations by the ligated intestinal segment and oral inoculation methods in Escherichia coli infections in pigs, calves, lambs and rabbits. J Pathol Bacteriol 93, 499-529.

Söderlind, O., Thafvelin, B. \& Möllby, R. (1988). Virulence factors in Escherichia coli strains isolated from Swedish piglets with diarrhea. J Clin Microbiol 26, 879-884.

Spandau, D. F. \& Lee, C.-H. (1987). Determination of the promoter strength of the gene encoding Escherichia coli heat-stable enterotoxin II. J Bacteriol 169, 1740-1744.

Sprangler, B. D. (1992). Structure and function of cholera toxin and the related Escherichia coli heat-labile enterotoxin. Microbiol Rev 56, 622-647.

Sukumar, M., Rizo, J., Wall, M., Dreyfus, L. A., Kupersztoch, Y. M. \& Gierasch, L. M. (1995). The structure of Escherichia coli heatstable enterotoxin $b$ by nuclear magnetic resonance and circular dichroism. Protein Sci 4, 1718-1729.

Urban, R. G., Dreyfus, L. A. \& Whipp, S. C. (1990a). Construction of a bifunctional Escherichia coli heat-stable enterotoxin (STb)alkaline phosphatase fusion protein. Infect Immun 58, 3645-3652. Urban, R. G., Pipper, E. M., Dreyfus, L. A. \& Whipp, S. C. (1990b) High-level production of Escherichia coli STb heat-stable enterotoxin and quantification by a direct enzyme-linked immunosorbent assay. J Clin Microbiol 28, 2383-2388.

Urban, R. G., Pipper, E. M. \& Dreyfus, L. A. (1991). Monoclonal antibodies specific for the Escherichia coli heat-stable enterotoxin STb. J Clin Microbiol 29, 1963-1968.

Weikel, C. S. \& Guerrant, R. L. (1985). STb enterotoxin of Escherichia coli: cyclic nucleotide-independent secretion. In Microbial Toxins and Diarrhoeal Disease (Ciba Foundation Symposium 112), pp. 94-115. London: Pitman.

Weikel, C. S., Long-Krug, S. \& Guerrant, R. L. (1986a). E. coli STb: a new mechanism for secretory diarrhea? In Advances in Research on Cholera and Related Diarrheas, pp. 333-341. Edited by S. Kuwahara \& N. F. Pierce. Tokyo: KTK Scientific.

Weikel, C. S., Nellans, H. N. \& Guerrant, R. L. (1986b). In vivo and in vitro effects of a novel enterotoxin, $\mathrm{ST} b$, produced by Escherichia coli. J Infect Dis 153, 893-901.

Weikel, C. S., Tiemens, K. M., Moseley, S. L., Huq, I. M. \& Guerrant, R. L. (1986c). Species specificity and lack of production of STb enterotoxin by Escherichia coli strains isolated from humans with diarrheal illness. Infect Immun 52, 323-325.

Whipp, S. C. (1987). Protease degradation of Escherichia coli heatstable, mouse-negative, pig-positive enterotoxin. Infect Immun 55, 2057-2060.

Whipp, S. C. (1990). Assay for enterotoxigenic Escherichia coli heat-stable toxin b in rats and mice. Infect Immun 58, 930-934.

Whipp. S. C. (1991). Intestinal responses to enterotoxigenic Escherichia coli heat-stable toxin b in non-porcine species. Am J Vet Res 52, 734-737.

Whipp, S. C., Moon, H. W. \& Argenzio, R. A. (1981). Comparison of enterotoxic activities of heat-stable enterotoxins from class 1 and class 2 Escherichia coli of swine origin. Infect Immun 31, 245-251.

Whipp, S. C., Moon, H. W., Kemeny, L. J. \& Argenzio, R. A. (1985). 
Effect of virus-induced destruction of villous epithelium on intestinal secretion induced by heat-stable Escherichia coli enterotoxins and prostaglandin $\mathrm{E}_{1}$ in swine. Am J Vet Res 46, $637-642$.

Whipp, S. C., Moseley, S. L. \& Moon, H. W. (1986). Microscopic alterations in jejunal epithelium of 3-week-old pigs induced by pig-specific, mouse-negative, heat-stable Escherichia coli enterotoxin. Am J Vet Res 47, 615-618.

Whipp, S. C., Kokue, E., Morgan, R. W., Rose, R. \& Moon, H. W.
(1987). Functional significance of histologic alterations induced by Escherichia coli pig-specific, mouse-negative, heat-stable enterotoxin (STb). Vet Res Commun 11, 41-55.

Wilson, R. A. \& Francis, D. H. (1986). Fimbriae and enterotoxins associated with Escherichia coli serogroups isolated from pigs with colibacillosis. Am J Vet Res 47, 213-217.

Woodward, M. J. \& Wray, C. (1990). Nine DNA probes for detection of toxin and adhesin genes in Escherichia coli isolated from diarrhoeal disease in animals. Vet Microbiol 25, 55-65. 